\title{
Advances in Mineral Processing and Hydrometallurgy
}

\author{
Corby G. Anderson * and Hao Cui *
}

Kroll Institute for Extractive Metallurgy, Mining Engineering Department \& George S. Ansell Department of Metallurgical and Materials Engineering, Colorado School of Mines, Golden, CO 80401, USA

* Correspondence: cganders@mines.edu (C.G.A.); hcuimetallurgy@outlook.com (H.C.)

Citation: Anderson, C.G.; Cui, H. Advances in Mineral Processing and Hydrometallurgy. Metals 2021, 11, 1393. https://doi.org/10.3390/ met11091393

Received: 19 August 2021

Accepted: 26 August 2021

Published: 1 September 2021

Publisher's Note: MDPI stays neutral with regard to jurisdictional claims in published maps and institutional affiliations.

Copyright: (c) 2021 by the authors. Licensee MDPI, Basel, Switzerland. This article is an open access article distributed under the terms and conditions of the Creative Commons Attribution (CC BY) license (https:/ / creativecommons.org/licenses/by/ $4.0 /)$.

\section{Introduction and Scope}

A Special Issue of Metals was commissioned that was devoted to aspects of Mineral Processing and Hydrometallurgy. The editors were Prof. Dr. Corby Anderson and Dr. Hao Cui. This issue was designed to include submissions for characterization, along with recycling and waste minimization, mineralogy, geometallurgy, thermodynamics, kinetics, comminution, classification, physical separations, liquid solid separations, leaching, solvent extraction, ion exchange, activated carbon, precipitation, reduction, process economics, and process control. Suggested application areas were gold, silver, PGMs, aluminum, copper, zinc, lead, nickel, and titanium. Critical metal articles on topics such as lithium, antimony, tellurium, gallium, germanium, cobalt, graphite, indium, and the rare earth metals were welcome. Thirty-one high-quality peer-reviewed articles from around the globe were selected and accepted for inclusion.

\section{Contributions}

Wang et al. [1] contributed an article entitled "Comparison of Butyric Acid Leaching Behaviors of Zinc from Three Basic Oxygen Steelmaking Filter Cakes". The selective leaching of zinc from three different basic oxygen steelmaking (BOS) filter cakes by butyric acid was investigated to compare the leaching behaviors of zinc and to further establish the correlation between the zinc leaching performance and chemical composition. The effects of acid concentration and the acid to solid (L/S) stoichiometric ratio were studied, with different optimal leaching conditions being obtained. BOS-1 showed the lowest leachability, with only less than $10 \%$ of zinc removed by a $0.5 \mathrm{M}$ acid concentration and $90 \%$ of the $\mathrm{L} / \mathrm{S}$ stoichiometric ratio in $10 \mathrm{~h}$. The best zinc selectivity was achieved with BOS-2 at $51.2 \%$ of the zinc leaching efficiency, with only $0.47 \%$ of iron loss under the optimal conditions of a $1.5 \mathrm{M}$ acid concentration and a 70\% stoichiometric ratio. BOS-3 showed the highest leaching of zinc, but the optimal conditions depended on priority consideration. Using $1.0 \mathrm{M}$ acid and a $90 \%$ stoichiometric ratio for $10 \mathrm{~h}$, the leaching efficiency of zinc was $84.6 \%$ with $20 \%$ iron loss. The filter cakes and the leaching residues were characterized. The results indicated different zinc and iron leaching behaviors, which were probably related to the storage conditions, zinc-containing phases, and the leaching parameters.

Toro et al. [2] provided an article entitled "Leaching of Pure Chalcocite in a Chloride Media Using Sea Water and Waste Water". Chalcocite is the most important and abundant secondary copper ore in the world, with a rapid dissolution of copper in an acid-chloride environment. In this investigation, the surface optimization methodology will be applied to evaluate the effect of three independent variables (time, concentration of sulfuric acid, and chloride concentration) in the leaching of pure chalcocite to extract the copper with the objective of obtaining a quadratic model that allows us to predict the extraction of copper. The kinetics of copper dissolution with regard to the function of temperature are also analyzed. An ANOVA indicated that the linear variables with the greatest influence are time and the chloride concentration. Moreover, the concentration of chloride-time exerts a significant synergic effect in the quadratic model. The ANOVA indicated that the quadratic model is representative and that the $R^{2}$ value of 0.92 is valid. The highest copper 
extraction $(67.75 \%)$ was obtained at $48 \mathrm{~h}$ leaching under the conditions of $2 \mathrm{~mol} / \mathrm{L} \mathrm{H}_{2} \mathrm{SO}_{4}$ and $100 \mathrm{~g} / \mathrm{L}$ chloride. The XRD analysis shows the formation of a stable and non-polluting residue, such as elemental sulfur $\left(\mathrm{S}^{0}\right)$. This residue was obtained in a leaching time of $4 \mathrm{~h}$ at room temperature under the conditions of $0.5 \mathrm{~mol} / \mathrm{L} \mathrm{H}_{2} \mathrm{SO}_{4}$ and $50 \mathrm{~g} / \mathrm{L} \mathrm{Cl}^{-}$.

Benavente et al. [3] submitted an article entitled "Copper Dissolution from Black Copper Ore under Oxidizing and Reducing Conditions". Black copper oxides are amorphous materials of copper-bearing phases of manganese. They are complex mineral compounds with difficult-to-recognize mineralogy and have slow dissolution kinetics in conventional hydrometallurgical processes. This study evaluates the effects of various leaching media on copper dissolution from black copper minerals. The leaching of a pure black copper sample from Lomas Bayas Mine and another from a regional mine were characterized by inductively coupled plasma atomic emission spectroscopy (ICP-AES), X-ray diffraction (XRD), scanning electron microscopy (SEM), and Qemscan and were mechanically prepared for acid leaching under standard, oxidizing, and reducing conditions through the addition of oxygen, iron sulfate, or sulfur dioxide, respectively. Standard and high-potential leaching (770 $\mathrm{mV}(\mathrm{SHE})$ ) resulted in a copper dissolution rate of $70 \%$ and manganese dissolution rate of $2 \%$. The addition of potential reducing agents $\left(\mathrm{FeSO}_{4}\right.$ or $\left.\mathrm{SO}_{2}\right)$ decreased the redox potential to 696 and $431 \mathrm{mV}$, respectively, and favored the dissolution of manganese, thus increasing the overall copper extraction rate. The addition of $\mathrm{SO}_{2}$ resulted in the lowest redox potential and the highest copper extraction rates of $86.2 \%$ and $75.5 \%$ for the Lomas Bayas and regional samples, respectively, which represent an increase of $15 \%$ over the copper extract rates under standard and oxidizing conditions.

Coello-Velázquez et al. [4] provided an article entitled "Use of the Swebrec Function to Model Particle Size Distribution in an Industrial-Scale Ni-Co Ore Grinding Circuit". Mathematical models of particle size distribution (PSD) are necessary in the modelling and simulation of comminution circuits. In order to evaluate the application of the Swebrec PSD model (SWEF) in the grinding circuit at the Punta Gorda Ni-Co plant, a sampling campaign was conducted with variations in the operating parameters. Subsequently, the fitting of the data to the Gates-Gaudin-Schumann (GGS), Rosin-Rammler (RRS), and SWEF PSD functions was evaluated under statistical criteria. The fitting of the evaluated distribution models showed that these functions are characterized as being sufficiently accurate, as the estimation error does not exceed 3.0\% in any of the cases. In the particular case of the Swebrec function, the reproducibility for all of the products was high. Furthermore, its estimation error did not exceed $2.7 \%$ in any of the cases, with a correlation coefficient of the ratio between the experimental and simulated data greater than 0.99 .

Soria-Aguilar et al. [5] contributed an article entitled "Oxidative Leaching of Zinc and Alkalis from Iron Blast Furnace Sludge". The sludge from a wet-off gas cleaning system of an iron blast furnace (BF) contains significant amounts of iron; however, this iron cannot be recycled due to its high content of zinc and alkalis. These compounds are detrimental to the optimal performance of iron and steelmaking furnaces. In this work, a comparative laboratory study to reduce zinc and alkali contained in the blast furnace sludge (BFS) is presented. The effect of leaching parameters, such as oxidants (i.e., ferric ion, oxygen, or ozone), aqueous solution media (i.e., $0.2 \mathrm{M} \mathrm{NH}_{4} \mathrm{Cl}, 0.2 \mathrm{M} \mathrm{HCl}$, and $0.1 \mathrm{M} \mathrm{H}_{2} \mathrm{SO}_{4}$ ), and temperature (i.e., 27 and $\left.80^{\circ} \mathrm{C}\right)$ on $\mathrm{Zn}$ and alkali $\left(\mathrm{Na}_{2} \mathrm{O}\right.$ and $\left.\mathrm{K}_{2} \mathrm{O}\right)$ removal were studied by applying an experimental design. The obtained results show that $\mathrm{Zn}$ and $\mathrm{K}_{2} \mathrm{O}$ removals of $85 \%$ and $75 \%$ were achieved under the following conditions: ozone as an oxidant agent and $0.1 \mathrm{M} \mathrm{H}_{2} \mathrm{SO}_{4}$ as an aqueous medium; temperature had no significant effect. The results are supported by thermodynamic diagrams and the possible chemical reactions are mentioned. Although the results also indicate that leaching under the above conditions dissolves up to $9 \%$ of iron, this loss is much less than leaching without the oxidizing conditions generated by the ozone. The BFS obtained from this treatment could be recirculated to the iron or steelmaking processes to recover iron values.

Pérez et al. [6] contributed an article entitled "Extraction of Mn from Black Copper Using Iron Oxides from Tailings and $\mathrm{Fe}^{2+}$ as Reducing Agents in Acid Medium". Exotic- 
type deposits include several species of minerals, such as atacamite, chrysocolla, copper pitch, and copper wad. Among these, copper pitch and copper wad have considerable concentrations of manganese. However, their non-crystalline and amorphous structure makes it challenging to recover elements of interest (such as $\mathrm{Cu}$ or $\mathrm{Mn}$ ) using conventional hydrometallurgical methods. For this reason, black copper ores are generally not incorporated into the extraction circuits or left unprocessed, whether in stock, leach pads, or waste. Therefore, to dilute $\mathrm{MnO}_{2}$, the use of reducing agents is essential. In the present research, agitated leaching was performed to dissolve the Mn of black copper in an acidic medium, comparing the use of ferrous ions and tailings as reducing agents. Two samples of black copper were studied, of high and low grade of Mn, respectively, the latter with a high content of clays. The effect of the reducing agent/black copper ratio and the concentration of sulfuric acid in the system was evaluated. Better results in removing Mn were achieved using the highest-grade black copper sample when working with ferrous ions at a ratio of $\mathrm{Fe}^{2+} /$ black copper of $2 / 1$ and $1 \mathrm{~mol} / \mathrm{L}$ of sulfuric acid. Moreover, the low-grade sample induced significant $\mathrm{H}_{2} \mathrm{SO}_{4}$ consumption due to the high presence of gangue and clays.

Jeldres et al. [7] authored an article entitled "Viscoelasticity of Quartz and Kaolin Slurries in Seawater: Importance of Magnesium Precipitates". In this study, the viscoelastic properties of quartz and kaolin suspensions in seawater were analysed considering two distinct conditions: $\mathrm{pH} 8$ and 10.7. Creep and oscillatory sweep tests provided the rheological parameters. An Anton Paar MCR 102 rheometer (ANAMIN Group, Santiago, Chile) was used with a vane-in-cup configuration, and the data were processed with RheoCompass ${ }^{\mathrm{TM}}$ Light software (ANAMIN Group, Santiago, Chile). The outcomes were associated with the formation of solid species principally composed of magnesium precipitates. The magnesium in the solution reduced from 1380 to $1280 \mathrm{mg} / \mathrm{L}$ in the presence of quartz (68 wt \%). Since the difference was not large regarding the solid-free seawater, the disposition of the solid complexes at $\mathrm{pH} 10.7$ was expected to be similar. The jump in $\mathrm{pH}$ caused both yield stress and viscoelastic moduli to drop, suggesting that the solid precipitates diminished the strength of the particle networks that made up the suspension. For the kaolin slurries (37 wt \%), the yield stress increased when the $\mathrm{pH}$ increased, but unlike quartz, there was a significant adsorption of magnesium cations. In fact, the concentration of magnesium in solution fell from 1380 to $658 \mathrm{mg} / \mathrm{L}$. Dynamic oscillatory assays revealed structural changes in both pulps; in particular, the phase angle was greater at $\mathrm{pH} 8$ than at pH 10.7, which indicates that at more alkaline conditions, the suspension exhibits a more solid-like character.

Sokić et al. [8] contributed a manuscript entitled "Kinetics of Chalcopyrite Leaching by Hydrogen Peroxide in Sulfuric Acid". In ores, chalcopyrite is usually associated with other sulfide minerals, such as sphalerite, galena, and pyrite, in a dispersed form with complex mineralogical structures. Concentrates obtained by the flotation of such ores are unsuitable for pyrometallurgical processing, owing to their poor quality and low metal recovery. This paper presents the leaching of chalcopyrite concentrate from the location of Rudnik, Serbia. The samples from the flotation plant were treated with hydrogen peroxide in sulfuric acid. The influences of temperature, particle size, and stirring speed as well as the concentrations of hydrogen peroxide and sulfuric acid were followed and discussed. Hence, the main objective was to optimize the relevant conditions and to determine the reaction kinetics. It was remarked that the increase in temperature, hydrogen peroxide content, and sulfuric acid concentration as well as the decrease in particle size and stirring speed contribute to the dissolution of chalcopyrite. The dissolution kinetics follow a model controlled by diffusion, and the lixiviant diffusion controls the rate of reaction through the sulfur layer. Finally, the main characterization methods used to corroborate the obtained results were $\mathrm{X}$-ray diffraction (XRD) as well as the qualitative and quantitative light microscopy of the chalcopyrite concentrate samples and the leach residue.

Jeldres et al. [9] contributed their research entitled "Copper Tailing Flocculation in Seawater: Relating the Yield Stress with Fractal Aggregates at Varied Mixing Conditions". The implications of the physical conditions of the feedwell on the rheological properties of 
synthetic copper tailings flocculated in seawater were analyzed. The mixing intensity of flocculation was related to the structural characteristics of the aggregates, and the outcomes were linked to the yield stress of the pulp sediments. Tailing settling assays were conducted using a $30 \mathrm{~mm}$ turbine type stirrer with an in situ aggregate size characterization. The structural characteristics of the aggregates were determined using the focused beam reflectance measurement (FBRM). After mixing time between the pulp and the flocculant, the sample was allowed to settle for $2.5 \mathrm{~h}$, where the variation of the sediment height was minimal. The sediment was gently removed and was subjected to rheological characterization. The yield stress was measured on an Anton Paar MCR 102 rheometer (ANAMIN Group, Santiago, Chile) with a vane-in-cup configuration. The mixing intensity was related to the characteristics of the aggregates, and the outcomes were linked to the yield stress of the flocculated pulp sediments. More aggressive hydrodynamics deteriorated the structure of the aggregates, promoting the reduction of both its size and the fractal dimension. This brought direct consequences to the rheological properties of the sediments: at a higher mixing level, the yield stress was lower. The explanation lies in the structural changes of the aggregates, where at a fixed mixing rate, the yield stress presented a seemingly exponential increase over the fractal dimension. Additionally, correlations were found between the rheological properties regarding settling rate and aggregate size.

Torres et al. [10] provide an article entitled "Leaching Manganese Nodules in an Acid Medium and Room Temperature Comparing the Use of Different Fe Reducing Agents". The deposits of Fe-Mn in the seabed of the planet are a good alternative source for the extraction of elements of interest. Among these are marine nodules, which contain approximately $24 \%$ manganese and may be a solution to the shortage of high-grade ores on the surface. In this investigation, an ANOVA analysis was performed to evaluate the time-independent variables and the $\mathrm{MnO}_{2}$ /reducing agent in the leaching of manganese nodules with the use of different Fe reducing agents $\left(\mathrm{FeS}_{2}, \mathrm{Fe}^{2+}, \mathrm{Fe}^{0}\right.$ and $\left.\mathrm{Fe}_{2} \mathrm{O}_{3}\right)$. Tests were also conducted for the different reducing agents evaluating the $\mathrm{MnO}_{2} / \mathrm{Fe}$ ratio, in which the $\mathrm{Fe}^{0}(\mathrm{FeC})$ proved to be the best reducing agent for the dissolution of $\mathrm{Mn}$ from marine nodules, achieving solutions of $97 \%$ in $20 \mathrm{~min}$. In addition, it was discovered that, at low $\mathrm{MnO}_{2} / \mathrm{Fe}$ ratios, the acid concentration in the system is not very relevant, and the potential and $\mathrm{pH}$ were in ranges of $-0.4-1.4 \mathrm{~V}$ and $-2-0.1$, favoring the dissolution of $\mathrm{Mn}$ from $\mathrm{MnO}_{2}$.

Karimov et al. [11] submitted two articles. The first is entitled "Leaching Kinetics of Arsenic Sulfide-Containing Materials by Copper Sulfate Solution". The overall decrease in the quality of mineral raw materials, combined with the use of arsenic-containing ores, results in large amounts of various intermediate products containing this highly toxic element. The use of hydrometallurgical technologies for these materials is complicated by the formation of multicomponent solutions and the difficulty of separating copper from arsenic. Previously, for the selective separation of As from copper-arsenic intermediates, a leaching method in the presence of $\mathrm{Cu}$ (II) ions was proposed. This paper describes the investigation of the kinetics of arsenic sulfide-containing materials leaching due to copper sulfate solution. After the leaching of arsenic trisulfide with a solution of copper sulfate, the cakes were described using methods such as X-ray diffraction spectrometry (XRD), X-ray fluorescence spectrometry (XRF), scanning electron microscopy (SEM), and energy-dispersive $\mathrm{X}$-ray spectroscopy analysis (EDS). The effect of temperature $\left(70-90^{\circ} \mathrm{C}\right)$, the initial concentration of $\mathrm{CuSO}_{4}(0.23-0.28 \mathrm{M})$, and the time on the As recovery into the solution were studied. The process temperature has the greatest effect on the kinetics, while an increase in copper concentration from 0.23 to $0.28 \mathrm{M}$ effects an increase in As transfer into a solution from $93.2 \%$ to $97.8 \%$ for $120 \mathrm{~min}$ of leaching. However, the shrinking core model that best fits the kinetic data suggests that the process occurs via the intra-diffusion mode, with an average activation energy of $44.9 \mathrm{~kJ} / \mathrm{mol}$. Using the time-to-a-given-fraction kinetics analysis, it was determined that the leaching mechanism does not change during the reaction. The semi-empirical expression describing the reaction rate under the studied conditions can be written as follows: $1 / 3 \ln (1-X)+[(1-X)-1 / 3-1]=4560000 \mathrm{Cu}^{3.61} \mathrm{e}^{-44900 / R T} t$. 
Salinas-Rodriguez et al. [12] offered a publication entitled "Assessment of Silica Recovery from Metallurgical Mining Waste, by Means of Column Flotation". The generation of mining waste commonly leads to the use of spaces for its disposal. Challenges such as mitigating the damage to surrounding communities have promoted the need to reuse, recycle, and/or reduce their generation. Moreover, these residues may become the source of materials that are capable of being recovered and reused in several industries, minimizing their environmental impact. In the mining region of Pachuca, Mexico, waste from the mining industry has been generated for more than 100 years and has a high $\mathrm{SiO}_{2}$ content that can be recovered for various industrial applications. This work aims to recover silica from a material from the Dos Carlos dam. A columnar system composed of two-stage of cleaning was used, considering a $J_{L T}$ (surface liquid rate) value of 0.45 and $0.68 \mathrm{~cm} / \mathrm{s}$, respectively, while the $J_{g}$ (surface gas rate) value was $0.30 \mathrm{~cm} / \mathrm{s}$ for both stages. Similar bubble sizes in the range of $J_{g} 0.10$ to $0.30 \mathrm{~cm} / \mathrm{s}$, with values between 0.14 and $0.16 \mathrm{~cm}$ were found in the first stage, and those that were 0.05 to $0.06 \mathrm{~cm}$ in size were found in the second one. This provided a recovery of $75.10 \%$ for all of the allotropic phases of silica (quartz, trydimite, and cristobalite), leaving a concentration of $24.90 \%$ for the feldspathic phase (orthoclase) as flotation tails.

Torres et al. [13] authored a submission entitled "Leaching Chalcopyrite with High $\mathrm{MnO}_{2}$ and Chloride Concentrations". Most copper minerals are found as sulfides, with chalcopyrite being the most abundant. However, this ore is refractory to conventional hydrometallurgical methods, so it has been historically exploited through froth flotation followed by smelting operations. This implies that the processing involves polluting activities, either by the formation of tailings dams or the emission of large amounts of $\mathrm{SO}_{2}$ into the atmosphere. Given increasing environmental restrictions, it is necessary to consider new processing strategies that are compatible with the environment, and, if feasible, combine the reuse of industrial waste. In the present research, the dissolution of pure chalcopyrite was studied, considering the use of $\mathrm{MnO}_{2}$ and wastewater with a high chloride content. Fine particles $(-20 \mu \mathrm{m})$ generated an increase in the extraction of copper from the mineral. Moreover, it was discovered that while working at high temperatures $\left(80^{\circ} \mathrm{C}\right)$, large concentrations of $\mathrm{MnO}_{2}$ become irrelevant. The biggest copper extractions of this work $(71 \%)$ were achieved when operating at $80^{\circ} \mathrm{C}$, with a particle size of $-47+38 \mu \mathrm{m}$, a $\mathrm{MnO}_{2} / \mathrm{CuFeS}_{2}$ ratio of $5 / 1$, and $1 \mathrm{~mol} / \mathrm{L}$ of $\mathrm{H}_{2} \mathrm{SO}_{4}$.

Roldán-Contreras et al. [14] contributed an article entitled "Leaching of Silver and Gold Contained in a Sedimentary Ore, Using Sodium Thiosulfate; A Preliminary Kinetic Study". Some sedimentary minerals have attractive contents of gold and silver, similar to the sedimentary exhalative ore available in the eastern Hidalgo in Mexico. The gold and silver contained represent an interesting opportunity for processing via non-toxic and aggressive leaching reagents such as thiosulfate. The preliminary kinetic study indicated that the leaching process was poorly affected by temperature and thiosulfate concentration. The reaction order was -0.61 for $\mathrm{Ag}$, considering a thiosulfate concentration between $200-500 \mathrm{~mol} \cdot \mathrm{m}^{-3}$, while for $\mathrm{Au}$, it was -0.09 for a concentration range between $32-320 \mathrm{~mol} \cdot \mathrm{m}^{-3}$. By varying the $\mathrm{pH}$ between $7-10$, it was found that the reaction order was $n=5.03$ for $\mathrm{Ag}$, while for $\mathrm{Au}$, the value was $n=0.94$ when considering $\mathrm{pH}$ 9.5-11. The activation energy obtained during the silver leaching process was $3.15 \mathrm{~kJ} \cdot \mathrm{mol}^{-1}(298-328 \mathrm{~K})$, which was indicative of the diffusive control of the process. On the other hand, during gold leaching, the obtained activation energy was $36.44 \mathrm{~kJ} \cdot \mathrm{mol}^{-1}$, which was indicative that this process was a mixed controlled process, first at low temperatures by diffusive control (298-313 K), and then by chemical control (318-323 K).

Rodríguez et al. [15] offered their research paper entitled "Leaching Chalcopyrite with an Imidazolium-Based Ionic Liquid and Bromide". The unique properties of ionic liquids (ILs) drive the growing number of novel applications in different industries. The main features of ILs are their high thermal stability, recyclability, low flash point, and low vapor pressure. This study investigated pure chalcopyrite dissolution in the presence of the ionic

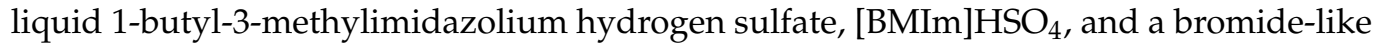


complexing agent. The proposed system was compared to acid leaching in sulfate media with the addition of chloride and bromide ions. The results demonstrated that the use of ionic liquid and bromide ions improved chalcopyrite leaching performance. The best operational conditions were at a temperature of $90^{\circ} \mathrm{C}$, with an ionic liquid concentration of $20 \%$ and $100 \mathrm{~g} / \mathrm{L}$ of bromide.

Castellón et al. [16] contributed an article entitled "Depression of Pyrite in Seawater Flotation by Guar Gum". The application of guar gum for pyrite depression in seawater flotation was assessed through microflotation tests, focused beam reflectance measurements (FBRM), and particle vision measurements (PVM). Potassium amyl xanthate (PAX) and methyl isobutyl carbinol (MIBC) were used as a collector and frother, respectively. Chemical species on the pyrite surface were characterized by Fourier-transform infrared (FTIR) spectroscopy. The microflotation tests were performed at $\mathrm{pH} \mathrm{8,} \mathrm{which} \mathrm{is} \mathrm{the} \mathrm{pH}$ at the copper sulfide processing plants that operate with seawater. Pyrite flotation recovery was correlated with FBRM and PVM characterization to delineate the pyrite depression mechanisms by the guar gum. The high flotation recovery of pyrite with PAX was significantly lowered by guar gum, indicating that this polysaccharide could be used as an effective depressant in flotation with sea water. FTIR analysis showed that PAX and guar gum co-adsorbed on the pyrite surface, but the highly hydrophilic nature of the guar gum embedded the hydrophobicity due to the PAX. FBRM and PVM revealed that the guar gum promoted the formation of flocs whose size depended on the addition of guar gum and PAX. It is proposed that the highest pyrite depression occurred not only because of the hydrophilicity induced by the guar gum, but also due to the formation of large flocs, which could not be transported by the bubbles to the froth phase. Furthermore, it is shown that an overdose of guar gum hinders the depression effect due to the redispersion of the flocs.

Quezada et al. [17] submitted a work entitled "Describing Mining Tailing Flocculation in Seawater by Population Balance Models: Effect of Mixing Intensity". A population balance model (PBM) was used to describe the flocculation of particle tailings in seawater at $\mathrm{pH} 8$ for a range of mixing intensities. The size of the aggregates is represented by the mean chord length, determined by the focused beam reflectance measurement (FBRM) technique. The PBM follows the dynamics of aggregation and breakage processes underlying flocculation and provides a good approximation to the temporal evolution of aggregate size. The structure of the aggregates during flocculation is described by a constant or time-dependent fractal dimension. The results revealed that the compensation between the aggregation and breakage rates leads to a correct representation of the flocculation kinetics of the tailings of particles in seawater and, in addition, that the representation of the flocculation kinetics in optimal conditions is equally good with a constant or variable fractal dimension. The aggregation and breakage functions and their corresponding parameters are sensitive to the choice of the fractal dimension of the aggregates, whether they are constant or time-dependent; however, under optimal conditions, a constant fractal dimension is sufficient. The model is robust and predictive with a few parameters and can be used to find the optimal flocculation conditions at different mixing intensities, and the optimal flocculation time can be used for a cost-effective evaluation of the quality of the flocculant used.

Matsumoto et al. [18] reported their research entitled "Selective and Mutual Separation of Palladium (II), Platinum (IV), and Rhodium (III) Using Aliphatic Primary Amines". The selective recovery of platinum-group metals (PGMs) remains a huge challenge. Although solvent extraction processes are generally used for PGM separation, the use of organic solvents is problematic because of their toxicity and environmental concerns. Here, we have developed a new PGM recovery method by means of precipitation from hydrochloric acid $(\mathrm{HCl})$ solutions containing $\mathrm{Pd}(\mathrm{II}), \mathrm{Pt}(\mathrm{IV})$, and $\mathrm{Rh}(\mathrm{III})$, using aliphatic primary amines as precipitants. $\mathrm{Pt}(\mathrm{IV})$ was precipitated using the amines with alkyl chains longer than the hexyl, independent of $\mathrm{HCl}$ concentration. The precipitation of $\mathrm{Pd}(\mathrm{II})$ required longer alkyl amines than octyl, regardless of the $\mathrm{HCl}$ concentration. $\mathrm{Rh}(\mathrm{III})$ was recovered by precipitation at high $\mathrm{HCl}$ concentrations using the amines longer than hexyl. The mutual separation 
of $\mathrm{Pt}(\mathrm{IV}), \mathrm{Rh}(\mathrm{III})$, and $\mathrm{Pd}(\mathrm{II})$, in this order, was successfully achieved by changing the $\mathrm{HCl}$ concentrations and alkyl chain lengths of the amines. X-ray photoelectron spectroscopy and thermogravimetric analysis evidently showed that the metal-containing precipitates were ion-pair complexes composed of metal chloro-complex anions and ammonium cations.

Quezada et al. [19] submitted their work entitled "Reducing the Magnesium Content from Seawater to Improve Tailing Flocculation: Description by Population Balance Models". Experimental assays and mathematical models, through population balance models (PBM), were used to characterize the particle aggregation of mining tailings flocculated in seawater. Three systems were considered for the preparation of the slurries: (i) seawater at natural $\mathrm{pH}$ ( $\mathrm{pH} 7.4)$, (ii) seawater at $\mathrm{pH} 11$, and (iii) treated seawater at $\mathrm{pH} 11$. The treated seawater had reduced magnesium content in order to avoid the formation of solid complexes, which damage the concentration operations. For this, the $\mathrm{pH}$ of seawater was increased with lime before being used in the process, generating solid precipitates of magnesium that were removed by means of vacuum filtration. The mean size of the aggregates was represented by the mean chord length obtained with the focused beam reflectance measurement (FBRM) technique, and their descriptions, obtained by the PBM, showed that an aggregation and a breakage kernel had evolved. The fractal dimension and permeability were included in the model in order to improve the representation of the irregular structure of the aggregates. Then, five parameters were optimized: three for the aggregation kernel and two for the breakage kernel. The results show that raising the $\mathrm{pH}$ from 8 to 11 was severely detrimental to the flocculation performance. Nevertheless, for $\mathrm{pH} 11$, the aggregates slightly exceeded $100 \mu \mathrm{m}$, causing undesirable behaviour during the thickening operations. Interestingly, magnesium removal provided a suitable environment to perform the tailing flocculation at alkaline $\mathrm{pH}$, creating aggregates with sizes that exceeded $300 \mu \mathrm{m}$. Only the fractal dimension changed between $\mathrm{pH} 8$ and treated seawater at $\mathrm{pH} 11$-as reflected in the permeability outcomes. The PBM fit well with the experimental data, and the parameters showed that the aggregation kernel was dominant at all-polymer dosages. The descriptive capacity of the model might have been utilized as a support in practical decisions regarding the best-operating requirements in the flocculation of copper tailings and water clarification.

Cui et al. [20] submitted a research effort entitled "Hydrometallurgical Treatment of Waste Printed Circuit Boards: Bromine Leaching". This paper demonstrates the recovery of valuable metals from shredded waste-printed circuit boards (WPCBs) by bromine leaching. The effects of the sodium bromide concentration, bromine concentration, leaching time, and inorganic acids were investigated. The most critical factors were sodium concentration and bromine concentration. It was found that more than $95 \%$ of copper, silver, lead, gold, and nickel could be dissolved simultaneously under the optimal conditions: a $50 \mathrm{~g} / \mathrm{L}$ solid/liquid ratio, 1.17 M NaBr, 0.77 $\mathrm{M} \mathrm{Br}_{2}, 2 \mathrm{M} \mathrm{HCl}$, a $400 \mathrm{RPM}$ agitation speed, and $23.5^{\circ} \mathrm{C}$ for $10 \mathrm{~h}$. The study shows that the dissolution of gold from waste-printed circuit boards in a $\mathrm{Br}_{2}-\mathrm{NaBr}$ system is controlled by film diffusion and chemical reaction.

Prasetyo et al. [21] authored an innovative article entitled "Platinum Group Elements Recovery from Used Catalytic Converters by Acidic Fusion and Leaching". The recovery of platinum group elements (PGE (platinum group element coating); Pd, Pt, and Rh) from used catalytic converters using low energy and fewer chemicals was developed using a potassium bisulfate fusion pretreatment and were subsequently leached using hydrochloric acid. In the fusion pre-treatment, potassium bisulfate alone (without the addition of an oxidant) proved to be an effective and selective fusing agent. It altered PGE into a more soluble species and did not react with the cordierite support, based on X-ray diffraction (XRD) and metallographic characterization results. The fusion efficacy was due to the transformation of bisulfate into pyrosulfate, which is capable of oxidizing PGE. However, the introduction of potassium through the fusing agent proved to be detrimental in general since the potassium formed insoluble potassium PGE chloro-complexes during leaching (decreasing the recovery) and required a higher $\mathrm{HCl}$ concentration and a higher leaching temperature to restore solubility. Optimization of the fusion and leaching parameters resulted in $106 \% \pm 1.7 \%, 93.3 \% \pm 0.6 \%$, and $94.3 \% \pm 3.9 \%$ recovery for $\mathrm{Pd}, \mathrm{Pt}$, and $\mathrm{Rh}$, 
respectively. These results were achieved at the following fusion conditions: temperature $550^{\circ} \mathrm{C}$, potassium bisulfate/raw material mass ratio 2.5 , and fusion time within $30 \mathrm{~min}$. The leaching conditions were a $\mathrm{HCl}$ concentration $5 \mathrm{M}$, a temperature of $80^{\circ} \mathrm{C}$, and a time within $20 \mathrm{~min}$.

Torres et al. [10] contributed a revised article entitled "Leaching Manganese Nodules in an Acid Medium and Room Temperature Comparing the Use of Different Fe Reducing Agents". The deposits of Fe-Mn in the seabed of the planet are a good alternative source for the extraction of elements of interest. Among these are marine nodules, which have approximately $24 \%$ manganese and may be a solution to the shortage of high-grade ores on the surface. In this investigation, an ANOVA analysis was performed to evaluate the time-independent variables and the $\mathrm{MnO}_{2}$ /reducing agent in the leaching of manganese nodules with the use of different $\mathrm{Fe}$ reducing agents $\left(\mathrm{FeS}_{2}, \mathrm{Fe}^{2+}, \mathrm{Fe}^{0}\right.$ and $\left.\mathrm{Fe}_{2} \mathrm{O}_{3}\right)$. Tests were also conducted for the different reducing agents evaluating the $\mathrm{MnO}_{2} / \mathrm{Fe}$ ratio, in which the $\mathrm{Fe}^{0}(\mathrm{FeC})$ proved to be the best reducing agent for the dissolution of $\mathrm{Mn}$ from marine nodules, achieving solutions of $97 \%$ in $20 \mathrm{~min}$. In addition, it was discovered that at low $\mathrm{MnO}_{2} / \mathrm{Fe}$ ratios, the acid concentration in the system is not very relevant, and the potential and $\mathrm{pH}$ were in ranges of $-0.4-1.4 \mathrm{~V}$ and $-2-0.1$, favoring the dissolution of $\mathrm{Mn}$ from $\mathrm{MnO}_{2}$.

Castellón et al. [22] authored a submission entitled "An Alternative Process for Leaching Chalcopyrite Concentrate in Nitrate-Acid-Seawater Media with Oxidant Recovery". An alternative copper concentrate leaching process using sodium nitrate and sulfuric acid diluted in seawater followed by gas scrubbing to recover the sodium nitrate was evaluated. The work involved a leaching test conducted under various conditions with varying temperatures, leaching times, particle sizes, and concentrations of $\mathrm{NaNO}_{3}$ and $\mathrm{H}_{2} \mathrm{SO}_{4}$. Regarding the amount of copper extracted from the chalcopyrite concentrate leached with seawater, $0.5 \mathrm{M}$ of $\mathrm{H}_{2} \mathrm{SO}_{4}$ and $0.5 \mathrm{M}$ of $\mathrm{NaNO}_{3}$, copper recovery increased from $78 \%$ at room temperature to $91 \%$ at $45^{\circ} \mathrm{C}$ after $96 \mathrm{~h}$ and $46 \mathrm{~h}$ of leaching, respectively. Gas scrubbing with the alkaline solution of $\mathrm{NaOH}$ was explored to recover part of the sodium nitrate. The dissolved salts were recovered by evaporation as sodium nitrate and sodium nitrite crystals.

Cho et al. [23] offered a novel concept paper entitled "Recovery of Gold from the Refractory Gold Concentrate Using Microwave Assisted Leaching". Microwave technology has been confirmed to be suitable for use in a wide range of mineral leaching processes. Compared to conventional leaching, microwave-assisted leaching has significant advantages. It is a proven process because of its short processing time and reduced energy. The purpose of this study was to enhance the gold content in a refractory gold concentrate using microwave-assisted leaching. The leaching efficiencies of metal ions ( $\mathrm{As}, \mathrm{Cu}, \mathrm{Zn}, \mathrm{Fe}$, and $\mathrm{Pb}$ ) and the recovery of gold from refractory gold concentrate were investigated via nitric acid leaching followed by microwave treatment. As the acid concentration increased, the metal ion leaching increased. In the refractory gold concentrate leaching experiments, nitric acid leaching at high temperatures could limit the decomposition of sulfide minerals because of the passive layer in the refractory gold concentrate. Microwave-assisted leaching experiments for gold recovery were conducted for the refractory gold concentrate. More extreme reaction conditions (nitric acid concentration $>1.0 \mathrm{M}$ ) facilitated the decomposition of passivation species derived from metal ion dissolution and the liberation of gangue minerals on the sulfide surface. The recovery rate of gold in the leach residue was improved with microwave-assisted leaching, with a gold recovery of $\sim 132.55 \mathrm{~g} / \mathrm{t}$ after $20 \mathrm{~min}$ of the leaching experiment (2.0 M nitric acid), according to fire assays.

Valeev et al. [24] produced a research article entitled "Acid and Acid-Alkali Treatment Methods of Al-Chloride Solution Obtained by the Leaching of Coal Fly Ash to Produce Sandy Grade Alumina". Sandy grade alumina is a valuable intermediate material that is mainly produced by the Bayer process and is used for manufacturing primary metallic aluminum. Coal fly ash is generated in coal-fired power plants as a by-product of coal combustion that consists of submicron ash particles and is considered to be a potentially 
hazardous technogenic waste. The present paper demonstrates that the Al-chloride solution obtained by leaching coal fly ash can be further processed to obtain sandy grade alumina, which is essentially suitable for metallic aluminum production. The novel process developed in the present study involves the production of amorphous alumina via the calcination of aluminium chloride hexahydrate obtained by salting-out from acid $\mathrm{Al}-\mathrm{Cl}$ liquor. Following this, alkaline treatment with further $\mathrm{Al}_{2} \mathrm{O}_{3}$ dissolution and recrystallization as $\mathrm{Al}(\mathrm{OH})_{3}$ particles is applied, and a final calcination step is employed to obtain sandy grade alumina with minimum impurities. The process does not require high-pressure equipment and reutilizes the alkaline liquor and gibbsite particles from the Bayer process, which allows the sandy grade alumina production costs to be significantly reduced. The present article also discusses the main technological parameters of the acid treatment and the amounts of major impurities in the sandy grade alumina obtained by the different (acid and acid-alkali) methods.

Prasetyo et al. [25] provide novel research in "Monosodium Glutamate as Selective Lixiviant for Alkaline Leaching of Zinc and Copper from Electric Arc Furnace Dust". The efficacy of monosodium glutamate (MSG) as a lixiviant for the selective and sustainable leaching of zinc and copper from electric arc furnace dust was tested. Batch leaching studies and XRD, XRF, and SEM-EDS characterization confirmed the high leaching efficiency of zinc (reaching 99\%) and copper (reaching $86 \%$ ), leaving $\mathrm{Fe}, \mathrm{Al}, \mathrm{Ca}$, and $\mathrm{Mg}$ behind in the leaching residue. The separation factor (concentration ratio in pregnant leach solution) between zinc vs. other elements and copper vs. other elements in the optimum conditions could reach 11,700 and 250 times, respectively. The optimum conditions for the leaching scheme were a pH of 9, a MSG concentration of $1 \mathrm{M}$, and a pulp density of $50 \mathrm{~g} / \mathrm{L}$. Kinetic studies (leaching time and temperature) revealed that the saturation value of the leaching efficiency was attained within $2 \mathrm{~h}$ for zinc and within $4 \mathrm{~h}$ for copper. Modeling of the kinetic experimental data indicated that the role of temperature on the leaching process was minor. The study also demonstrated the possibility of MSG recycling from pregnant leach solutions by precipitation as glutamic acid ( $>90 \%$ recovery).

Karimov et al. [26] furthered the understanding of ammoniacal hydrometallurgy with their work entitled "Effect of Preliminary Alkali Desilication on Ammonia Pressure Leaching of Low-Grade Copper-Silver Concentrate". Ammonia leaching is a promising method for processing low-grade copper ores, especially those containing large amounts of oxidized copper. In this paper, we study the effect of Si-containing minerals on the kinetics of $\mathrm{Cu}$ and $\mathrm{Ag}$ leaching from low-grade copper concentrates. The results of experiments on the pressure leaching of the initial copper concentrate in an ammonium/ammonium carbonate solution with oxygen as an oxidizing agent are in good agreement with the shrinking core model in the intra-diffusion mode: in this case, the activation energies were $53.50 \mathrm{~kJ} / \mathrm{mol}$ for $\mathrm{Cu}$ and $90.35 \mathrm{~kJ} / \mathrm{mol}$ for Ag. Energy-dispersive X-ray spectroscopy analysis (EDX) showed that reagent diffusion to $\mathrm{Cu}$-bearing minerals can be limited by aluminosilicate minerals of the gangue. The recovery rate for copper and silver increases significantly after a preliminary alkaline desilication of the concentrate, and the new shrinking core model is the most adequate, showing that the process is limited by diffusion through the product layer and interfacial diffusion. The activation energy of the process increases to $86.76 \mathrm{~kJ} / \mathrm{mol}$ for $\mathrm{Cu}$ and to $92.15 \mathrm{~kJ} / \mathrm{mol}$ for Ag. Using the time-to-a-given-fraction method, it has been shown that a high activation energy is required in the later stages of the process, when the most resistant sulfide minerals of copper and silver apparently remain.

Aracena et al. [27] also contributed further insights into ammoniacal hydrometallurgy with their contribution "Mechanism and Kinetics of Malachite Dissolution in an $\mathrm{NH}_{4} \mathrm{OH}$ System". Copper oxide minerals composed of carbonates consume high quantities of leaching reagent. The present research proposes an alternative procedure for malachite leaching $\left(\mathrm{Cu}_{2} \mathrm{CO}_{3}(\mathrm{OH})_{2}\right)$ through the use of only one compound, ammonium hydroxide $\left(\mathrm{NH}_{4} \mathrm{OH}\right)$. Preliminary studies were also conducted for the dissolution of malachite in an acid system. The variables evaluated were solution $\mathrm{pH}$, stirring rate, temperature, $\mathrm{NH}_{4} \mathrm{OH}$ concentration, particle size, solid/liquid ratio, and different ammonium reagents. The 
experiments were conducted in a stirred batch system with controlled temperatures and stirring rates. For the acid dissolution system, sulfuric acid consumption reached excessive values (986 $\mathrm{kg} \mathrm{H}_{2} \mathrm{SO}_{4} /$ ton of malachite), invalidating the dissolution in these common systems. On the other hand, for the ammoniacal system, there was no acid consumption, and the results show that copper recovery was very high, reaching values of $84.1 \%$ for a concentration of $0.2 \mathrm{~mol} / \mathrm{dm}^{3}$ of $\mathrm{NH}_{4} \mathrm{OH}$ and an experiment time of $7200 \mathrm{~s}$. The theoreti$\mathrm{cal} /$ thermodynamic calculations indicate that the solution $\mathrm{pH}$ was a significant factor in maintaining the copper soluble as $\mathrm{Cu}\left(\mathrm{NH}_{3}\right)_{4}^{2+}$. This was validated by the experimental results and solid analysis by $\mathrm{X}$-ray diffraction $(\mathrm{XRD})$ from which the reaction mechanisms were obtained. A heterogeneous kinetic model was obtained from the diffusion model in a porous layer for the particles that begin the reaction as nonporous but that become porous during the reaction as the original solid splits and cracks to form a highly porous structure. The reaction order for the $\mathrm{NH}_{4} \mathrm{OH}$ concentration was 3.2 and was inversely proportional to the square of the initial radius of the particle. The activation energy was calculated at $36.1 \mathrm{~kJ} / \mathrm{mol}$ in the temperature range of 278 to $313 \mathrm{~K}$.

Zhang et al. [28] provide a review of rare earth recycling entitled "Hydrometallurgical Recovery of Rare Earth Elements from NdFeB Permanent Magnet Scrap: A Review". NdFeB permanent magnet scrap is regarded as an important secondary resource that contains rare earth elements (REEs) such as Nd, Pr, and Dy. Recovering these valuable REEs from the $\mathrm{NdFeB}$ permanent magnet scrap not only increases economic potential, but also helps to reduce problems related to disposal and the environment. Hydrometallurgical routes are considered to be the primary choice for recovering the REEs because of the applications of higher REE recovery to all types of magnet compositions. In this paper, the authors first reviewed the chemical and physical properties of $\mathrm{NdFeB}$ permanent magnet scrap and then conducted an in-depth discussion on a variety of hydrometallurgical processes for recovering REEs from the $\mathrm{NdFeB}$ permanent magnet scrap. The methods mainly included selective leaching or complete leaching processes followed by precipitation, solvent extraction, or ionic liquid extraction processes. Particular attention is devoted to the specific technical challenge that emerges in the hydrometallurgical recovery of REEs from $\mathrm{NdFeB}$ permanent magnet scrap and to the corresponding potential measures for improving REE recovery by promoting processing efficiency. This summarized review will be useful for researchers who are developing processes for recovering REEs from $\mathrm{NdFeB}$ permanent magnet scrap.

Cho et al. [29] furthered our understanding of lithium refining by authoring "Application of Multistage Concentration (MSC) Electrodialysis to Concentrate Lithium from Lithium-Containing Waste Solution". In order to manufacture lithium carbonate to be used as a raw material for a secondary lithium battery, lithium sulfate solution is used as a precursor, and the concentration of lithium is required to be $10 \mathrm{~g} / \mathrm{L}$ or more. Electrodialysis (ED) was used as a method to concentrate lithium in a low-concentration lithium sulfate solution, and multistage concentration (MSC) electrodialysis was used to increase the concentration ratio (\%). When MSC was performed using a raw material solution containing a large amount of sodium sulfate, the process lead time was increased by $60 \mathrm{~min}$. Furthermore, the concentration ratio (\%) of lithium decreased as the number of concentration stages increased. In order to remove sodium sulfate, methanol was added to the raw material solution to precipitate sodium sulfate, and when it was added in a volume ratio of 0.4 , lithium was not lost. Using a solution in which sodium sulfate was partially removed, fourth-stage concentration ED was performed to obtain a lithium sulfate solution with a lithium concentration of $10 \mathrm{~g} / \mathrm{L}$.

Medina and Anderson [30] provided an insightful document, "Review of the Cyanidation Treatment of Copper-Gold Ores and Concentrates". Globally, copper, silver, and gold orebody grades have been dropping, and the mineralogy surrounding them has become more diversified and complex. The cyanidation process for gold production has remained dominant for over 130 years because of its selectivity and feasibility in the mining industry. For this reason, the industry has been adjusting its methods for the extraction of gold by 
utilizing more efficient processes and technologies. Often, gold may be found in conjunction with copper and silver in ores and concentrates. Hence, the application of cyanide to these types of ores can present some difficulty, as the diversity of the minerals found within these ores can cause the application of cyanidation to become more complicated. This paper outlines the practices, processes, and reagents proposed for the effective treatment of these ores. The primary purpose of this review paper is to present the hydrometallurgical processes that currently exist in the mining industry for the treatment of silver, copper, and gold ores as well as for concentration treatments. In addition, this paper aims to present the most important challenges that the industry currently faces so that future processes that are both more efficient and feasible may be established.

\section{Summary and Outlook}

This Special Issue of Metals was well supported by diverse submissions and a final publication of thirty-one high-quality peer-reviewed articles. It is anticipated that due to this success, a new Special Issue ("Advances in Mineral Processing and Hydrometallurgy II", website: https://www.mdpi.com/journal/metals/special_issues/mineral_process_ hydrometallurgy2) will be commissioned as a follow-up to accept global contributions from the hydrometallurgy and mineral processing community.

Conflicts of Interest: The authors declare no conflict of interest.

\section{References}

1. Wang, J.; Wang, Z.; Zhang, Z.; Zhang, G. Comparison of Butyric Acid Leaching Behaviors of Zinc from Three Basic Oxygen Steelmaking Filter Cakes. Metals 2019, 9, 417. [CrossRef]

2. Toro, N.; Briceño, W.; Pérez, K.; Cánovas, M.; Trigueros, E.; Sepúlveda, R.; Hernández, P. Leaching of Pure Chalcocite in a Chloride Media Using Sea Water and Waste Water. Metals 2019, 9, 780. [CrossRef]

3. Benavente, O.; Hernández, M.; Melo, E.; Núñez, D.; Quezada, V.; Zepeda, Y. Copper Dissolution from Black Copper Ore under Oxidizing and Reducing Conditions. Metals 2019, 9, 799. [CrossRef]

4. Coello-Velázquez, A.; Quijano Arteaga, V.; Menéndez-Aguado, J.; Pole, F.; Llorente, L. Use of the Swebrec Function to Model Particle Size Distribution in an Industrial-Scale Ni-Co Ore Grinding Circuit. Metals 2019, 9, 882. [CrossRef]

5. Soria-Aguilar, M.; Davila-Pulido, G.; Carrillo-Pedroza, F.; Gonzalez-Ibarra, A.; Picazo-Rodriguez, N.; Lopez-Saucedo, F.; RamosCano, J. Oxidative Leaching of Zinc and Alkalis from Iron Blast Furnace Sludge. Metals 2019, 9, 1015. [CrossRef]

6. $\quad$ Pérez, K.; Toro, N.; Campos, E.; González, J.; Jeldres, R.; Nazer, A.; Rodriguez, M. Extraction of Mn from Black Copper Using Iron Oxides from Tailings and $\mathrm{Fe}^{2+}$ as Reducing Agents in Acid Medium. Metals 2019, 9, 1112. [CrossRef]

7. Jeldres, M.; Piceros, E.; Robles, P.; Toro, N.; Jeldres, R. Viscoelasticity of Quartz and Kaolin Slurries in Seawater: Importance of Magnesium Precipitates. Metals 2019, 9, 1120. [CrossRef]

8. Sokić, M.; Marković, B.; Stanković, S.; Kamberović, Ž.; Štrbac, N.; Manojlović, V.; Petronijević, N. Kinetics of Chalcopyrite Leaching by Hydrogen Peroxide in Sulfuric Acid. Metals 2019, 9, 1173. [CrossRef]

9. Jeldres, M.; Piceros, E.; Toro, N.; Torres, D.; Robles, P.; Leiva, W.; Jeldres, R. Copper Tailing Flocculation in Seawater: Relating the Yield Stress with Fractal Aggregates at Varied Mixing Conditions. Metals 2019, 9, 1295. [CrossRef]

10. Torres, D.; Ayala, L.; Saldaña, M.; Cánovas, M.; Jeldres, R.I.; Nieto, S.; Castillo, J.; Robles, P.; Toro, N. Leaching Manganese Nodules in an Acid Medium and Room Temperature Comparing the Use of Different Fe Reducing Agents. Metals 2019, 9, 1316; Correction in 2020, 10, 485. [CrossRef]

11. Karimov, K.; Rogozhnikov, D.; Kuzas, E.; Shoppert, A. Leaching Kinetics of Arsenic Sulfide-Containing Materials by Copper Sulfate Solution. Metals 2020, 10, 7. [CrossRef]

12. Salinas-Rodriguez, E.; Flores-Badillo, J.; Hernandez-Avila, J.; Cerecedo-Saenz, E.; Gutierrez-Amador, M.; Jeldres, R.; Toro, N. Assessment of Silica Recovery from Metallurgical Mining Waste, by Means of Column Flotation. Metals 2020, 10, 72. [CrossRef]

13. Torres, D.; Ayala, L.; Jeldres, R.; Cerecedo-Sáenz, E.; Salinas-Rodríguez, E.; Robles, P.; Toro, N. Leaching Chalcopyrite with High $\mathrm{MnO}_{2}$ and Chloride Concentrations. Metals 2020, 10, 107. [CrossRef]

14. Roldán-Contreras, E.; Salinas-Rodríguez, E.; Hernández-Ávila, J.; Cerecedo-Sáenz, E.; Rodríguez-Lugo, V.; Jeldres, R.I.; Toro, N. Leaching of Silver and Gold Contained in a Sedimentary Ore, Using Sodium Thiosulfate; A Preliminary Kinetic Study. Metals 2020, 10, 159. [CrossRef]

15. Rodríguez, M.; Ayala, L.; Robles, P.; Sepúlveda, R.; Torres, D.; Carrillo-Pedroza, F.; Jeldres, R.; Toro, N. Leaching Chalcopyrite with an Imidazolium-Based Ionic Liquid and Bromide. Metals 2020, 10, 183. [CrossRef]

16. Castellón, C.; Piceros, E.; Toro, N.; Robles, P.; López-Valdivieso, A.; Jeldres, R. Depression of Pyrite in Seawater Flotation by Guar Gum. Metals 2020, 10, 239. [CrossRef]

17. Quezada, G.; Ayala, L.; Leiva, W.; Toro, N.; Toledo, P.; Robles, P.; Jeldres, R.I. Describing Mining Tailing Flocculation in Seawater by Population Balance Models: Effect of Mixing Intensity. Metals 2020, 10, 240. [CrossRef] 
18. Matsumoto, K.; Sezaki, Y.; Yamakawa, S.; Hata, Y.; Jikei, M. Selective and Mutual Separation of Palladium (II), Platinum (IV), and Rhodium (III) Using Aliphatic Primary Amines. Metals 2020, 10, 324. [CrossRef]

19. Quezada, G.; Jeldres, M.; Toro, N.; Robles, P.; Jeldres, R. Reducing the Magnesium Content from Seawater to Improve Tailing Flocculation: Description by Population Balance Models. Metals 2020, 10, 329. [CrossRef]

20. Cui, H.; Anderson, C. Hydrometallurgical Treatment of Waste Printed Circuit Boards: Bromine Leaching. Metals 2020, 10, 462. [CrossRef]

21. Prasetyo, E.; Anderson, C. Platinum Group Elements Recovery from Used Catalytic Converters by Acidic Fusion and Leaching. Metals 2020, 10, 485. [CrossRef]

22. Castellón, C.; Hernández, P.; Velásquez-Yévenes, L.; Taboada, M. An Alternative Process for Leaching Chalcopyrite Concentrate in Nitrate-Acid-Seawater Media with Oxidant Recovery. Metals 2020, 10, 518. [CrossRef]

23. Cho, K.; Kim, H.; Myung, E.; Purev, O.; Choi, N.; Park, C. Recovery of Gold from the Refractory Gold Concentrate Using Microwave Assisted Leaching. Metals 2020, 10, 571. [CrossRef]

24. Valeev, D.; Shoppert, A.; Mikhailova, A.; Kondratiev, A. Acid and Acid-Alkali Treatment Methods of Al-Chloride Solution Obtained by the Leaching of Coal Fly Ash to Produce Sandy Grade Alumina. Metals 2020, 10, 585. [CrossRef]

25. Prasetyo, E.; Anderson, C.; Nurjaman, F.; Al Muttaqii, M.; Handoko, A.; Bahfie, F.; Mufakhir, F. Monosodium Glutamate as Selective Lixiviant for Alkaline Leaching of Zinc and Copper from Electric Arc Furnace Dust. Metals 2020, 10, 644. [CrossRef]

26. Karimov, K.; Shoppert, A.; Rogozhnikov, D.; Kuzas, E.; Zakhar'yan, S.; Naboichenko, S. Effect of Preliminary Alkali Desilication on Ammonia Pressure Leaching of Low-Grade Copper-Silver Concentrate. Metals 2020, 10, 812. [CrossRef]

27. Aracena, A.; Pino, J.; Jerez, O. Mechanism and Kinetics of Malachite Dissolution in an $\mathrm{NH}_{4} \mathrm{OH}$ System. Metals 2020, $10,833$. [CrossRef]

28. Zhang, Y.; Gu, F.; Su, Z.; Liu, S.; Anderson, C.; Jiang, T. Hydrometallurgical Recovery of Rare Earth Elements from NdFeB Permanent Magnet Scrap: A Review. Metals 2020, 10, 841. [CrossRef]

29. Cho, Y.; Kim, K.; Ahn, J.; Lee, J. Application of Multistage Concentration (MSC) Electrodialysis to Concentrate Lithium from Lithium-Containing Waste Solution. Metals 2020, 10, 851. [CrossRef]

30. Medina, D.; Anderson, C. A Review of the Cyanidation Treatment of Copper-Gold Ores and Concentrates. Metals 2020, $10,897$. [CrossRef] 